\title{
Phenolic antioxidants of bael fruit herbal tea and effects on postprandial glycemia and plasma antioxidant status in healthy adults
}

\author{
Anoma Chandrasekara ${ }^{a^{*}}$, Thavanthen Januka ${ }^{\mathrm{a}}$, Disna Kumaria \\ Adriano Costa de Camargo ${ }^{\mathrm{b}}$ and Fereidoon Shahidi ${ }^{\mathrm{c}}$
}

\begin{abstract}
aDepartment of Applied Nutrition, Wayamba University of Sri Lanka, Makandura, Gonawila, Sri Lanka, 60170
${ }^{b}$ Laboratory of Antioxidants, Nutrition and Food Technology Institute, University of Chile, Santiago, Chile

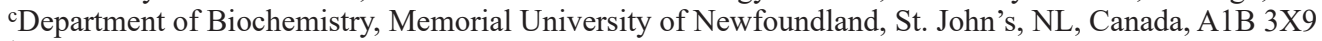

*Corresponding author: Anoma Chandrasekara, Department of Applied Nutrition, Wayamba University of Sri Lanka, Makandura, Gonawila, Sri Lanka, 60170. Tel: +94 (031) 2298120; E-mail: anomac@wyb.ac.lk, anomapriyan@yahoo.ca

DOI: $10.31665 /$ JFB.2020.11239

Received: August 11, 2020; Revised received \& accepted: September 13, 2020

Citation: Chandrasekara, A., Januka, T., Kumari, D., de Camargo, A.C., and Shahidi, F. (2020). Phenolic antioxidants of bael fruit herbal tea and effects on postprandial glycemia and plasma antioxidant status in healthy adults. J. Food Bioact. 11: 75-83.
\end{abstract}

\begin{abstract}
Herbal teas are globally popular among health conscious consumers. In this study the phenolic content and potential antioxidant activities of bael fruit herbal tea prepared with dried immature bael fruit cuts (Aegle marmelos), traditionally used in the Asia, were determined. Phenolic compounds of the herbal extracts were identified using liquid chromatography-tandem mass spectrometry. The total phenolic content (TPC) and antioxidant activities of the tested herbal extract was determined. The amount of herbal material to be used in the tea preparation was established based on the sensory evaluation conducted with 50 untrained adult panelists. The single dose efficacy of the bael fruit herbal tea on postprandial glycemic response and plasma antioxidant capacity (PAC) of healthy adults were investigated. A randomized crossover study was carried out with 16 healthy adults who consumed $250 \mathrm{~mL}$ bael fruit tea with $50 \mathrm{~g}$ glucose challenge and the control ( $50 \mathrm{~g}$ glucose in $250 \mathrm{~mL}$ water) randomly within two visits. Blood samples were collected at the baseline and postprandial at 30, 45, 60, 90, and 120 min using microcapillary tubes. The plasma was analyzed for glucose concentration (PGC) and PAC. The TPC of bael fruit tea extract was $108.3 \mu \mathrm{mol}$ gallic acid equivalents/g of extract. There was a reduction trend in mean PGC of those subjects who consumed bael fruit tea compared to the glucose added water (control) at each time point. Furthermore, the bael fruit tea significantly increased PAC at the end of $120 \mathrm{~min}$ post ingestion. Further research is warranted to examine the long-term efficacy of multiple dose ingestion of bael fruit herbal tea in the control and management of diseases associated with oxidative stress.
\end{abstract}

Keywords: Aglae marmelos; immature fruits; HPLC; TPC; single dose ingestion; Sri Lanka.

\section{Introduction}

Oxidative stress is a known underlying factor of metabolic syndrome and associated health conditions such as cardiovascular disease, diabetes, hypertension, as well as liver and kidney disorders
(Iannitti and Palmieri, 2009). Reactive oxygen species (ROS) and reactive nitrogen species (RNS) play a pivotal role in production of secondary complications of diabetes. Hyperglycemia leads to the generation of ROS which can damage cell membranes and form lipid peroxides which lead to atherosclerosis. 
There is a renewed recent interest on certain plants as complementary alternative medicine to prevent and manage non-communicable disease (NCD) conditions associated with dietary and lifestyle behavior. Plant products are rich in bioactive compounds and are more active in natural formulations than those of isolated components due to the synergistic, additive or antagonistic actions among compounds (Caesar and Cech, 2019).

Herbal teas play an important role among commonly consumed beverages such as tea, coffee and cocoa in the food cultures of many countries (Chandrasekara and Shahidi, 2018). Sri Lankan herbal teas are conventionally used as an alternative to regular tea (Camellia sinensis) and are popular among health-conscious consumers. In recent years, herbal teas have received much attention as natural health promoting products (Li et al., 2019). The type of herbal teas commonly consumed in different countries may be affected by local habits and availability of the respective plants. Herbal teas contain a number of bioactive compounds belonging to the group of carotenoids, phenolic acids, flavonoids, coumarins, alkaloids, polyacetylenes, saponins and terpenoids, among others. These bioactive compounds are responsible for several health effects, such as antioxidant, antibacterial, antiviral, anti-inflammatory, antihyperglycemic, antihyperlipidemic, anticarcinogenic and antiaging activities (Akalin et al., 2019; Chandrasekara and Shahidi, 2018; Chandrasekara et al., 2018; Kamalakkannan and Prince, 2005, 2003).

Aegle marmelos, known as Bengal quince, Indian quince, holy fruit, golden apple in English, and bael in Hindi and bilva in Sanskrit, belongs to the family Rutaceae. Bael is a tropical plant and is native to the Southeast Asian region in India, Sri Lanka, Pakistan, Bangladesh, Mianmar, and Thailand. Although the ripen fruit is most popular, different parts of bael tree, namely flowers and buds, unripe fruit, seeds, leaves, bark, branches, and roots are used for the treatment of a number of ailments in traditional Ayurvedic medical system (Dhankhar et al., 2011). The bark as well as fruit are used as ethnomedicine for dysentery and various intestinal complaints. Several bioactivities, such as antiulcer, antimalarial, anti-inflammatory, radioprotective, analgesic, antibacterial, antiviral, anti-dyslipidemic, anticancer and antidiabetic activities of parts of bael tree have been reported (Dhankhar et al., 2011; Kamalakkannan and Prince, 2005; Rajadurai and Prince, 2005; Arul et al. 2005; Jagetia et al. 2004; 2005; Dhuley, 2004; Badam et al. 2002; Misra et al. 1991). Coumarins, alkaloids, tannins and other phenolic compounds, and carotenoids, are reported in different parts of bael tree (Baliga et al. 2011; Dhankhar et al. 2011; Maity et al. 2009). In a previous study, we reported the presence of several phenolic acids, namely vanillic, $p$-coumaric, chlorogenic, caffeic, and gentisic acids along with some flavonoids, mainly catechin, and quercetin in the extracts of dried bael flowers and buds (Chandrasekara et al. 2018).

Bael fruit is a source of vitamin $\mathrm{C}$, vitamin $\mathrm{A}$, thiamin, niacin and riboflavin as well as calcium and phosphorus. The ripe fruit is slightly sweet and is characteristically aromatic. The pulp of fully ripen Thai bael fruit contain both soluble, and insoluble dietary fiber at 11.2 , and $8.6 \mathrm{~g} / 100 \mathrm{~g}$ dry weight (dw), respectively (Suvimol and Pranee, 2008). Fruits of bael have been reported to contain several bioactive compounds such as marmelosin, marmelide, luvangetin, aurapten, psoralen, aegelin, scoparone, scopoletin, tannic acid, xanthotoxol and $\beta$-sitosterol and tannin (Maity et al., 2009; Kamalakkannan and Prince, 2005). Immature bael fruit cuts are dried and used to prepare tea by open boiling or as tea bags after making a powder in Sri Lanka.

A number of therapeutic effects of mature bael fruit are reported (Baliga et al., 2011; Dhankhar et al., 2011; Krushna et al., 2012). However, studies on beneficial health effects improved plasma an- tioxidant activities and hypoglycemic response of dried immature bael fruit tea upon ingestion have not been reported. The present study aimed to determine the phenolic content and antioxidant activities of teas prepared with dried immature bael fruits. Furthermore, the potential short-term efficacy of bael fruit herbal tea on postprandial glycemic response and plasma antioxidant capacity of healthy adults were evaluated.

\section{Materials and methods}

\subsection{Herbal samples}

Dried cuts of immature bael fruits (Aegle marmelos) were purchased from a local market in North Western Province in Sri Lan$\mathrm{ka}$. All samples were cleaned to remove debris and dust and dried under sunlight before use.

\subsection{Chemicals}

Sodium carbonate and ferric chloride were procured from Thomas Baker (Chemicals) Ltd. (Mumbai, India). Folin-Ciocalteu's reagent and sodium nitrite were purchased from Research Lab Fine Chem Industries (Mumbai, India). The compounds 2,2-diphenyl1-picrylhydrazyl (DPPH), 2,2'-azino-bis (3-ethylbenzothiazoline6-sulfonate)(ABTS), trolox, ferric chloride, ferrous chloride, 2,2-azobis (2-methylpropionamidine) dihydrochloride (AAPH), potassium ferricyanide, sodium chloride, gallic acid, catechin, ascorbic acid and methanol, were purchased from Sigma-Aldrich, (St Louis, MO, USA). The compound 3-(2-pyridyl)-5, 6-diphenyl1,2,4-triazine-4,4-disulfonic acid sodium salt (Ferrozine) was bought from SERVA Electrophoresis GmbH (Heildberg, Germany). Aluminum chloride, and dibasic potassium phosphate were purchased from Techno Pharm Chem (Delhi, India). Sodium hydroxide $(\mathrm{NaOH})$, and monobasic potassium phosphate, were bought from Loba Chem Pvt Ltd (Mumbai, India). Ethylenediaminetetraacetic acid trisodium salt $\left(\mathrm{Na}_{3} \mathrm{EDTA}\right)$ was purchased from Needham Market (Suffolk, UK). Ellagic acid, protocatechuic acid $(+)$-catechin, (-)-epicatechin were purchased from Sigma Aldrich Canada Ltd (Oakville, ON, Canada). Acetonitrile, and formic acid, were procured from Fisher Scientific Ltd (Ottawa, ON, Canada). Glucose GOD-PAP reagent was purchased from BIOLABO (Maizy, France)

\subsection{Herbal aqueous extracts preparation}

The hot water extracts were prepared by boiling dried immature fruit cuts of bael in water $(1: 15 ; \mathrm{w} / \mathrm{v})$ at $100{ }^{\circ} \mathrm{C}$ for $20 \mathrm{~min}$. The residues were filtered through medium porosity filter papers and extracts were freeze dried at $-55^{\circ} \mathrm{C}$, and 0.012 mbar (Alpha 1-4 LD plus CHRIST, Osterode am Harz, Germany). Lyophilized extracts were stored at $-80^{\circ} \mathrm{C}$ until used for further analysis.

\subsection{Identification and quantification of phenolic compounds- HPLC-DAD-ESI-MS analysis}

Phenolic composition of herbal tea aqueous extracts was determined by RP-HPLC analysis using an Agilent 1100 HPLC system (Agilent Technologies, Palo Alto, CA, USA) equipped with a G1311A quaternary pump, a G1379A degasser and a G1329A ALS 
automatic sampler, a G1330B ALS Therm, a G1316A COLCOM column compartment, a G1315B diode array detector (DAD) and a system controller linked to Chem Station Data handling system (Agilent Technologies) as explained by de Camargo et al. (2015). Separations were conducted with a SUPELCOSIL ${ }^{\text {TM }}$ LC-18 column $(4.6 \times 250 \mathrm{~mm}, 5 \mu \mathrm{m}$; Merck, Darmstad, Germany). The binary mobile phase consisted of $1 \%$ formic acid (eluent A) and $1 \%$ formic acid in acetonitrile (eluent B). Gradient elution was used as follows: $0 \mathrm{~min}, 100 \% \mathrm{~A} ; 5 \mathrm{~min}, 90 \% \mathrm{~A} ; 35 \mathrm{~min}, 85 \% \mathrm{~A}$; $45 \mathrm{~min}, 60 \% \mathrm{~A} ; 45$ to $50 \mathrm{~min} 60 \%$ A was maintained from 50 to $55 \mathrm{~min}$ eluent A was increased and $100 \% \mathrm{~A}$ at $55 \mathrm{~min}$. The flow rate was adjusted to $0.5 \mathrm{~mL} / \mathrm{min}$ and the detection of compounds was achieved at $280 \mathrm{~nm}$. Samples were filtered through a $0.45 \mu \mathrm{m}$ PTFE membrane syringe filter (Thermo Scientific, Rockwood, TN, USA) before injection.

Phenolic compounds were identified by comparing their relative retention times (RT), and UV spectra and ESI-MS spectra with authentic compounds. HPLC-MS analysis was performed under the HPLC analytical conditions explained above using an Agilent 1100 series capillary liquid chromatography/mass selective detector (LC/MSD) ion trap system in electrospray ionization (ESI) negative ion mode. Complete system control and data evaluation were achieved with Agilent LC/MSD Trap software (Agilent Technologies). The mass spectrometer was operated in scan range of $\mathrm{m} / \mathrm{z}$ 50-2,000; smart parameter setting using a drying gas $\left(\mathrm{N}_{2}\right)$ temperature of $350{ }^{\circ} \mathrm{C}$, drying gas flow $12 \mathrm{~L} / \mathrm{min}$, and nebulizer gas $\left(\mathrm{N}_{2}\right)$ pressure of 70 psi. A number of compounds, present in the extracts were tentatively identified using ESI-MS ${ }^{\mathrm{n}}$ and UV spectral data and literature and quantified as equivalents of the closely related available standards. The external standard method in which reference compounds were chromatographed under similar chromatographic conditions separately from samples was used for quantification purposes.

\subsection{Chemical analysis of test herbal extract}

\subsubsection{Determination of total phenolic content (TPC)}

The total phenolic content of herbal extracts was determined according to the method of Singleton and Rossi (1965) with slight modifications (Chandrasekara et al, 2018). Briefly, the lyophilized crude extract of herbal tea was dissolved in methanol to obtain a concentration of $1 \mathrm{mg} / \mathrm{mL}$. Folin Ciocalteu reagent $(0.25 \mathrm{~mL})$ was added to $50 \mathrm{~mL}$ centrifuge tubes containing $0.25 \mathrm{~mL}$ of extract and the contents were mixed thoroughly by vortexing. To the reaction mixture $0.5 \mathrm{~mL}$ of saturated sodium carbonate solution was added followed by the addition of distilled water $(4 \mathrm{~mL})$ with thorough mixing. Tubes were allowed to stand at room temperature in the dark for $35 \mathrm{~min}$ followed by centrifugation at $4,000 \times \mathrm{g}$ for 10 min (Refrigerated centrifuge 3-18R TOMOS Life Science Group, Belmont, MA, USA). The absorbance of the resulting blue color supernatant was read at $725 \mathrm{~nm}$ (UV-VIS Spectrophotometer, Labomed Inc, Culver City, CA, USA) using appropriate blanks for background subtraction. The content of total phenolics in the extract was determined using a standard curve prepared for gallic acid and expressed as $\mu \mathrm{mol}$ gallic acid equivalents (GAE) per gram of crude extract.

\subsubsection{Determination of total flavonoid content (TFC)}

Total flavonoid content was determined using a colorimet- ric method as previously described (Kim et al, 2003). In brief, a known volume $(1 \mathrm{~mL})$ of aliquot of the extract, dissolved in methanol $(1 \mathrm{mg} / \mathrm{mL})$, was mixed with $4 \mathrm{~mL}$ of distilled water in a $50 \mathrm{~mL}$ centrifuge tube and $0.3 \mathrm{~mL}$ of $5 \% \mathrm{NaNO}_{2}$ was then added to the tube and allowed to react for $5 \mathrm{~min}$. Subsequently, $0.3 \mathrm{~mL}$ of $10 \% \mathrm{AlCl}_{3}$ was added to the reaction mixture and allowed to stand for $1 \mathrm{~min}$. Finally, $2 \mathrm{~mL}$ of $1 \mathrm{M} \mathrm{NaOH}$ and $2.4 \mathrm{~mL}$ of distilled water were added and mixed immediately. Centrifuge tubes were kept in the dark at room temperature for $15 \mathrm{~min}$ followed by centrifugation at $4,000 \times \mathrm{g}$ for $5 \mathrm{~min}$. The absorbance was read at $510 \mathrm{~nm}$ against a blank prepared in a similar manner by replacing the extract with distilled water. A standard curve prepared with catechin was used to calculate total flavonoid content which was expressed as $\mu \mathrm{mol}$ catechin equivalents (CE) per gram of crude extract.

\subsubsection{DPPH radical scavenging activity (DRSA)}

The DPPH radical scavenging ability was determined by the method of Lee et al. (2007). The sample of $0.04 \mathrm{~mL}$ of extract $(1 \mathrm{mg} /$ $\mathrm{mL}$ in methanol) was added to the $1.96 \mathrm{~mL}$ of methanolic DPPH $(60 \mu \mathrm{M})$ solution. The mixture was vortexed and allowed to stand at room temperature in the dark for $20 \mathrm{~min}$. The absorbance of the solutions was read at $517 \mathrm{~nm}$ with appropriate blank. The DPPH radical scavenging activity was expressed as $\mu \mathrm{mol}$ trolox equivalents (TE) per gram of crude extract.

\subsubsection{Trolox equivalent antioxidant capacity (TEAC)}

The TEAC of the extract was determined as previously explained (Chandrasekara and Shahidi, 2010). AAPH $(2.5 \mathrm{mM})$ was mixed with ABTS $(100 \mathrm{mM})$ in saline phosphate buffer (PBS) (pH 7.4, $0.15 \mathrm{M} \mathrm{NaCl}$ ) to prepare the $\mathrm{ABTS}^{*+}$ solution. The solution was kept in a water bath at $60^{\circ} \mathrm{C}$ for 16 min and the flask was covered by aluminum foil to protect it from light. Medium porosity filter papers were used to filter the prepared $\mathrm{ABTS}^{*+}$ solution before mixing with the extract. A separate blank was used to compensate for the diminished absorbance of radical solution. PBS solution was used to prepare herbal extract $(1 \mathrm{mg} / \mathrm{mL})$ and further diluted to fit within the range of $6.25-50 \mu \mathrm{M}$ of the standard curve prepared using trolox. To measure the TEAC, $40 \mu \mathrm{L}$ of the extract were mixed with $1,960 \mu \mathrm{L}$ of the $\mathrm{ABTS}^{\cdot+}$ solution. The absorbance of the reaction mixture was read at $734 \mathrm{~nm}$ immediately at the point of mixing $\left(\mathrm{t}_{0}\right)$ and after $6 \mathrm{~min}\left(\mathrm{t}_{6}\right)$. The decrease in absorbance at $734 \mathrm{~nm}$ after $6 \mathrm{~min}$ of addition of trolox and extract was calculated using the equation: $\Delta \mathrm{A}$ trolox $=\left(\mathrm{At}_{0}\right.$, trolox $-\mathrm{At}_{6}$, trolox $)-\left(\mathrm{At}_{0}\right.$, blank $-\mathrm{At}_{6}$, blank), where $\Delta \mathrm{A}$ is the reduction of absorbance and $\mathrm{A}$ is the absorbance at a given time. TEAC values were expressed as $\mu$ mol trolox equivalents (TE)/g of crude extract.

\subsubsection{Reducing power (RP)}

The RP of the sample was determined using a spectrophotometric method as explained by Kumari et al. (2017). Briefly, the extract $(0.5 \mathrm{~mL})$ was mixed with $1.25 \mathrm{~mL}$ of phosphate buffer solution $(0.2 \mathrm{M}, \mathrm{pH} 6.6)$ and $1.25 \mathrm{~mL}$ of potassium ferricyanide in a centrifuge tube. The mixture was incubated for $20 \mathrm{~min}$ at $50{ }^{\circ} \mathrm{C}$ and 1.25 $\mathrm{mL}$ of $10 \%$ TCA were added followed by centrifugation at 1,750 $\times \mathrm{g}$ for $10 \mathrm{~min}$. The supernatant $(1 \mathrm{~mL})$ was transferred into a tube containing $1.25 \mathrm{~mL}$ of deionized water and $0.25 \mathrm{~mL}$ of $0.1 \%(\mathrm{w} / \mathrm{v})$ $\mathrm{FeCl}_{3}$, and the absorbance was read using a spectrophotometer at 
$700 \mathrm{~nm}$. The results were expressed as $\mu$ mol ascorbic acid equivalents (AAE) per gram of crude extract using a standard curve prepared using ascorbic acid.

\subsubsection{Ferrous ion chelating activity (FICA)}

The ability of herbal tea extract to chelate ferrous ions was measured according to the method described by Kumari et al. (2017). The crude extract in distilled water $(1 \mathrm{mg} / \mathrm{mL})$ was used to measure chelating activity of ferrous ions. Briefly, $0.4 \mathrm{~mL}$ of extracts was added to a solution of $2 \mathrm{mM} \mathrm{FeCl}(0.05 \mathrm{~mL})$ followed by addition of $5 \mathrm{mM}$ ferrozine $(0.2 \mathrm{~mL})$. The total volume was adjusted to $4 \mathrm{~mL}$ with distilled water followed by vigorous vortexing. After standing for $10 \mathrm{~min}$ at room temperature, the absorbance of the reaction mixture was read at $562 \mathrm{~nm}$. Distilled water was used in place of the extract as the control. Appropriate blanks were prepared with $0.4 \mathrm{~mL}$ of the sample and $3.6 \mathrm{~mL}$ of distilled water for background subtraction. The inhibition percentage of ferrozine-ferrous ion complex formation was calculated using the following equation. Metal chelating effect $(\%)=\{1-$ (Absorbance of the sample/Absorbance of the control $)\} \times 100$. The percent inhibition of ferrozine-ferrous ion complex formation was calculated by the following equation: metal chelating effect (\%) $=[1-($ absorbance of the sample - absorbance of the control $)]$ 100. The results were expressed as $\mu \mathrm{mol}$ EDTA equivalents/per gram of crude extract

\subsection{Herbal tea preparation}

Three formulations of bael fruit tea were prepared with dried immature fruit cuts of bael in water $(1: 40,1: 20$, and $1: 10 ; \mathrm{w} / \mathrm{v})$. The quantities were based on the customary use of ingredients in Sri Lankan households. In preparation of the tea, ingredients were added to water and then allowed to boil for $20 \mathrm{~min}$ in medium heat followed by 20 min standing at room temperature. Residues were discarded by straining and the warm tea was used.

\subsection{Sensory evaluation of herbal teas}

Sensory properties were evaluated to determine the optimum level of herbal ingredient in the tea preparation. Fifty untrained panelists ( 25 males and 25 females in the age range of 24-40 years) were recruited for the sensory evaluation. The panelists were mainly students $(80 \%)$ and university staff $(20 \%)$ of the Makandura premises of Wayamba University of Sri Lanka. Three herbal teas, $50 \mathrm{~mL}$ each and coded with three digits, were served randomly to each panelist. Teas were served at the temperature range of $40-50{ }^{\circ} \mathrm{C}$ in transparent glass cups. The panelists rinsed their mouths with warm water before the commencement of tasting and in between each tasting of herbal teas. The panelists were instructed to wait 90 seconds before tasting the next sample and cracker biscuit was provided between tastings to eliminate any carry over effect. The panelists were not required to drink $50 \mathrm{~mL}$ of each bale fruit tea. They were asked to keep one sip of tea for 5 seconds in the mouth and swallow in small quantities. The panelists repeated tasting of the same tea whenever necessary.

The panelists scored in a 7 point hedonic scale for five attributes of the herbal tea. These included color, taste preference, after taste, overall acceptance, and willingness to drink regularly. In the hedonic scale 1 meant 'dislike very much' and 7 meant 'like very much'. The herbal tea performed with high score with majority of attributes favorably was selected for further experimentation based on the results of Frideman ranking test.

\subsection{Determination of phenolic content of the selected herbal tea}

The total phenolic content of the selected herbal tea based on sensory evaluation was determined as explained by Chandrasekara et al. (2018) using $0.25 \mathrm{~mL}$ of herbal tea. The TPC in the herbal tea was expressed as $\mu \mathrm{mol}$ GAE per $250 \mathrm{~mL}$ serving.

\subsection{Determination of antioxidant activity of the selected herbal teas}

Antioxidant activity of the selected herbal tea was determined by TEAC as explained by Chandrasekara and Shahidi (2010). The TEAC was expressed as $\mu \mathrm{mol}$ TE per $250 \mathrm{~mL}$ serving.

\subsection{Determination of glycemic response and plasma antioxi- dant capacity}

\subsubsection{Subjects}

Volunteers for the study were recruited through an opened advertisement from Makandura premises of Wayamba University of Sri Lanka. Written consent was obtained from each subject after explaining the study protocol before recruiting to the study. Ethical approval was obtained from the Ethics Review Committee of Faculty of Livestock, Fisheries and Nutrition, Wayamba University of Sri Lanka (201810HI06). Sixteen healthy individuals with fasting blood glucose between $70-110 \mathrm{mg} / \mathrm{dL}$ were recruited to the study after screening. Exclusion criteria included presence of any microvascular complications, alcohol and cigarette consumption, known allergies to herbal teas, and continuous use of any kind of medications.

\subsubsection{Protocol}

Two days prior to the test, participants were asked to restrict their intake of tea, including any herbal teas. Furthermore, they were restricted in intensive physical activities such as exercise and running. Each person made three visits and during the first visit anthropometric measurements (weight and height) and 24 hour dietary recall were taken from each participant. On each study visit, after 10-12 hours of fasting a blood sample was collected immediately before administering the herbal tea or control. The bael fruit tea $(250 \mathrm{~mL}$ of serving with $50 \mathrm{~g}$ glucose) and control (250 $\mathrm{mL}$ water with $50 \mathrm{~g}$ of glucose) were administered to participants randomly. The herbal tea and control were served in amber glass tumblers at same temperature level and panelists were advised to drink within $10 \mathrm{~min}$.

Finger prick blood samples were obtained at 30, 45, 60, 90 and $120 \mathrm{~min}$ after completing the drink using glass micro-hematocrit capillary tubes $(75 \mu \mathrm{L}$, sodium heparinized) for the determination of postprandial plasma glucose concentration (PGC). Only fasting and end point blood samples were taken for the determination of plasma antioxidant capacity (PAC) by finger pricking. The plasma was separated using micro-hematocrit centrifuge (Model HC-12A, Zenith Lab Inc, Brea, CA, USA) at 15,300 $\times$ g for 3 min and was 
Table 1. Phenolic compounds identified in bael fruit extracts

\begin{tabular}{llll}
\hline Compound & {$[\mathrm{M}-\mathrm{H}]^{-}(\mathrm{m} / \mathbf{z})$} & Other product ions $(\mathrm{m} / \mathbf{z})$ & Contents $(\boldsymbol{\mu g} / \mathbf{1 0 0} \mathrm{g})$ \\
\hline Ellagic acid & 301 & 283 & $0.04 \pm 0.003^{\mathrm{c}}$ \\
Protocatechuic acid derivative* & 337 & 153,109 & $25.63 \pm 0.86^{\mathrm{b}}$ \\
Resveratrol derivative** $^{*}$ & 433 & 227 & $497.8 \pm 17.2^{\mathrm{a}}$ \\
\hline
\end{tabular}

Data represent mean values for each sample \pm standard deviations $(n=3)$. Means followed by the same letter within a column are not significantly different $(p>0.05)$. ${ }^{*}$ uantified as equivalent of protocatechuic acid. ${ }^{* *}$ Quantified as equivalent of catechin. nd: not detected.

stored in Eppendorf tubes at $-80{ }^{\circ} \mathrm{C}$ for subsequent analysis of PGC and PAC.

\subsubsection{Determination of plasma glucose concentration}

Plasma glucose concentrations were determined by spectrophotometric method using a commercial kit (Glucose GOD-PAP liquid ready for use from BIOLABO (Maizy, France). Briefly, $10 \mu \mathrm{L}$ of plasma were mixed with $1 \mathrm{~mL}$ of reagent and was left for $20 \mathrm{~min}$ at room temperature $\left(30^{\circ} \mathrm{C}\right)$. The absorbance of the mixture was measured at $500 \mathrm{~nm}$ against the reagent blank. Plasma glucose values were calculated using the given standard concentration and expressed as $\mathrm{mg} / \mathrm{dL}$.

\subsubsection{Determination of plasma antioxidant capacity}

The TEAC assay described by Re et al. (1999) was used with minor modifications. The $\mathrm{ABTS}^{\bullet+}$ solution was prepared as explained by Chandrasekara and Shahidi (2010). The TEAC was measured by mixing $20 \mu \mathrm{L}$ of the plasma sample with $980 \mu \mathrm{L}$ of the ABTS ${ }^{*}$ solution. The absorbance value of the reaction mixture was read at $734 \mathrm{~nm}$ immediately at the point of mixing $\left(\mathrm{t}_{0}\right)$ and after 6 min $\left(\mathrm{t}_{6}\right)$. The decrease in absorbance at $734 \mathrm{~nm}$ after 6 min of addition of trolox and plasma was calculated using the following equation: $\Delta \mathrm{A}$ trolox $=\left(\mathrm{At}_{0}\right.$, trolox $-\mathrm{At}_{6}$, trolox $)-\left(\mathrm{At}_{0}\right.$, blank $-\mathrm{At}_{6}$, blank $)$, where $\Delta \mathrm{A}$ is the reduction of absorbance and $\mathrm{A}$ is the absorbance at a given time. TEAC values were expressed as $\mu \mathrm{mol}$ TE per L.

\subsection{Statistical analysis}

All experiments of chemical analysis of the herbal extract were carried out in triplicates and data were reported as mean \pm standard deviation. The mean ranking of sensory scores was determined using Friedman test (Milton, 1937). In the glycemic response efficacy study data were reported as mean \pm standard error of mean. The glycemic responses of the control and the herbal tea was compared using Bonferroni multiple comparison with $95 \%$ confidence interval (CI). The differences of group means at each time point were analyzed by paired $t$-tests with $95 \%$ CI. Plasma antioxidant capacities at the baseline and end of the group were compared using paired $t$-tests. All statistical analysis was performed by using SPSS version 23 (IBM Analytics, USA).

\section{Results and discussion}

In this study, phenolic content and antioxidant activities of immature dried bael fruit extracts were determined using different in vitro methods along with identification of compounds by HPLC${\mathrm{DAD}-E S I-M S^{\mathrm{n}}}$ analysis. Subsequently, a bael herbal tea prepara- tion, based on sensory characteristics, was selected and tested in a randomized single blind cross over design to determine the single dose efficacy on postprandial glycemic response and plasma antioxidant capacity of healthy adults.

\subsection{Identification of phenolic compounds}

Table 1 summarizes individual phenolic compounds and their contents from aqueous extracts of dried immature bael fruit cuts. Three compounds belonging to phenolic acids, and stilbenes were identified. Phenolic acids identified were ellagic acid and a derivative of protocatechuic acid. Ellagic acid was identified using an authentic standard and also due to the presence of a deprotonated ion at $\mathrm{m} / \mathrm{z} 301$ and $\mathrm{MS}^{2}$ at 283 (de Camargo et al., 2015). The second phenolic acid showed a deprotonated ion at $\mathrm{m} / \mathrm{z} 337$ and gave product ions at $\mathrm{m} / \mathrm{z} 153,119$ (protocatechuic acid) in $\mathrm{MS}^{2}$, which was confirmed using an authentic standard and literature data (de Camargo et al., 2015), thus tentatively identified as a protocatechuic acid derivative. Furthermore, a resveratrol derivative belonging to the group of stilbenoids was tentatively identified in the aqueous extract of immature bael fruits due to its $\mathrm{m} / \mathrm{z}$ of 433 in MS and $\mathrm{m} / \mathrm{z}$ of 227 in $\mathrm{MS}^{2}$, the latter being typical of resveratrol (Urpí-Sardà et al., 2005). In contrast to protocatechuic acid derivative, which gave product ions that allowed a better identification in $\mathrm{MS}^{2}$, the third compound (deprotonated ion at $\mathrm{m} / \mathrm{z} 301$ ) only showed one product ion $(\mathrm{m} / \mathrm{z}$ at 227$)$ in $\mathrm{MS}^{2}$. Therefore, to provide a putative information the compound was only tentatively identified as a resveratrol derivative and its further isolation and characterization by nuclear magnetic resonance (NMR) is deemed necessary. However, this is beyond the mandate of the present study and may be addressed in the future.

The tentatively identified derivative of resveratrol made the highest contribution to the phenolic profile, showing a content of $497.8 \mu \mathrm{g} / 100 \mathrm{~g}$. Resveratrol is a natural phytoalexin reported in a number of plant species and is mainly found in the skins and seeds of grapes as well as peanut skin (Salehi et al., 2018). Compounds identified in the matured bael fruit pulp in previous studies included monoterpenes, sesquiterpenes, coumarines, alkaloids, saponins, lignins, flavonoids and tannins, among others (Charoensiddhi and Anprung, 2008; Rajan et al., 2011). This is the first report on the presence of resveratrol or its derivatives in the extracts of bael fruit. It has been reported that resveratrol affects the nuclear factor kappa $\mathrm{B}(\mathrm{NF}-\mathrm{\kappa} \mathrm{B})$ signaling pathway which is responsible for the regulation of inflammation and immune responses (Kundu et al. 2006). Furthermore, beneficial therapeutic efficacy of resveratrol in a number of diseases such as cancers, obesity, neurological disorders, type 2 diabetes, cardiovascular diseases and non-alcoholic fatty liver diseases has been in focus though the bioavailability is low (Berman et al., 2017). In the present work extracts of immature bale fruits were used whereas previous studies had used pulp which is generally obtained from mature fruits. Furthermore, a recent study demonstrated that composition of active compounds 
Table 2. Phenolic contents and antioxidant activitieof aqueous bael fruit extract

\begin{tabular}{ll}
\hline Method & Results \\
\hline Total phenolic content $(\mu \mathrm{mol} \mathrm{GAE} / \mathrm{g})$ & $108.3 \pm 1.4$ \\
Total flavanoid content $(\mu \mathrm{mol} \mathrm{CE} / \mathrm{g})$ & $73.0 \pm 2.4$ \\
Trolox equivalent antioxidant capacity $(\mu \mathrm{mol} \mathrm{TE} / \mathrm{g})$ & $429.9 \pm 0.01$ \\
DPPH radical scavenging ability $(\mu \mathrm{mol} \mathrm{TE} / \mathrm{g})$ & $27.4 \pm 4.3$ \\
Reducing power $(\mu \mathrm{mol}$ AAE/g) & $122.1 \pm 4.2$ \\
Ferrous ion chelating ability $(\mu \mathrm{mol} \mathrm{EDTA} \mathrm{eq/g)}$ & $0.09 \pm 0.01$ \\
\hline
\end{tabular}

*Abbreviations are: GAE, gallic acid equivalents, CE, catechin equivalents; TE, trolox equivalents; AAE, ascorbic acid equivalents; EDTA, ethylenediaminetetraacetic acid; Eq, equivalents. Data represent mean values (three determinations) for each sample \pm standard deviations.

vary with the maturity stage of the bael fruit and was revealed that the level of phenolic compounds increased with the maturity of the fruit (Gurjar et al., 2019). Immature bale fruits contained higher levels of potassium, iron, marmelosin, psoralen and tannic acid compared with their mature counterparts (Gurjar et al., 2019).

\subsection{Total phenolic contents (TPC) of bael fruit extract}

Table 2 presents phenolic contents of the aqueous extract of immature bael fruit cuts. The TPC of bael fruit aqueous extract was $108.3 \mu \mathrm{mol} \mathrm{GAE} / \mathrm{g}$ of extract. Flavonoids are known to possess antioxidant, anticancer, antiallergic, anti-inflammatory, and antineuro-inflammatory properties, among others (Shahidi et al., 2019; de Camargo et al., 2019; Zhang and Tsao, 2016). The total flavonoid content (TFC) of the bael fruit extract was $73.0 \mu \mathrm{mol} \mathrm{CE} / \mathrm{g}$ extract (Table 2). According to Suvimol and Pranee (2008), TPC and TFC of $95 \%$ ethanolic extract of mature bael fruit pulp were $87.8 \mathrm{mg} \mathrm{GAE} / \mathrm{g} \mathrm{(dw)}$ and $15.2 \mathrm{mg} \mathrm{CE} / \mathrm{g}(\mathrm{dw})$, respectively. Thus, the results in this study demonstrate that aqueous extracts of dried bael immature fruits were rich sources of phenolic compounds.

\subsection{Antioxidant activities of bael fruit extracts}

Antioxidant activities of aqueous extracts of immature bael fruit cuts are presented in Table 2. TEAC of the bael fruit extract was $429.8 \mu \mathrm{mol} \mathrm{TE} / \mathrm{g}$ of extract. This assay is commonly used to assess antioxidant capacity of food and other biological matrices that reduce the ABTS radical cation to its non-radical form. The results are compared with that of trolox, the water soluble analogue of vitamin E, thus only water-soluble compounds in the extracts are measured.

$\mathrm{DPPH}$, a synthetic free radical, is widely used to evaluate radical scavenging properties of antioxidant compounds. In DRSA assay antioxidant compounds donate a hydrogen atom or an electron to the stable DPPH radical to convert it to the non-radical form (Yeo and Shahidi, 2019). DRSA of bael fruit extract was $27.4 \mu \mathrm{mol}$ TE/g of extract. Krushna et al. (2012) previously showed that bael fruit extract scavenged DPPH and $\mathrm{ABTS}^{+}$radical dose-dependently, in agreement with the findings of this study.

Activation of $\mathrm{NF}-\mathrm{kB}$ is mediated by oxidative stress. A recent study showed that samples exhibiting scavenging activity of $\mathrm{ABTS}^{+}$and DPPH radicals were effective in inhibiting the activa-

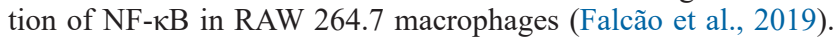
Thus, the present study showed that aqueous extracts of dried immature bael fruit cuts containing resveratrol possessed the capacity to inhibit both $\mathrm{ABTS}^{+}$and DPPH radicals and could serve as a potential candidate for inhibiting the activation of NF- $\mathrm{B}$ in bio- logical systems.

Compounds with reducing ability are capable of donating electrons and reduce the oxidized intermediates of peroxidation, hence acting as antioxidants. Reductants in herbal extracts reduce ferric/ ferricyanide complex to the ferrous form. RP of the tested extract of bael fruit herbal was $122.1 \mu \mathrm{mol}$ ascorbic acid equivalents/g extract. The immature bael fruit extract tested in the present work exhibited a considerable RP thereby acting as effective reducing agents.

FICA of of bael fruit extracts showed values of $0.09 \mu \mathrm{mol}$ EDTA equivalents/g extract in this study. By the action of ferrous ions in the body hydroxyl radicals are generated via Fenton's reaction and cause destruction of biomolecules leading to degenerative disease conditions and aging. Compounds that can act as chelating agents, reduce the concentration of metal ions available for catalyzing peroxidation thus serve as effective secondary antioxidants. Presence of chelating agents decreases the intensity of the purple color of the complex of ferrous ions with Ferrozine in the assay.

\subsection{Sensory evaluation}

Table 3 presents the results of sensory evaluation conducted for the three bael fruit tea preparations. The product 780 with 1:20 ratio of ingredient to water $(\mathrm{w} / \mathrm{v})$ received significantly $(\mathrm{p}<0.05)$ higher mean scores for taste preference, overall acceptability and willingness to drink regularly than others. The mean scores of untrained panelists for all attributes tested ranged between like slightly to like moderately for product 780 . The mean scores of color and after taste were not significantly different between the product 780 and product 892 with 1:40 (w/v) ingredient to water ratio. The product 531 with 1:10 (w/v) ingredient to water ratio received the least $(p<0.05)$ mean scores for all attributes tested. According to the Friedman test rank the product 780 obtained the highest mean rank of $2.41(p<0.05)$ and was selected for further studies as the most preferred bael tea.

\subsection{Phenolic content and antioxidant activities of selected bale fruit tea}

The TPC and TEAC of the selected bale fruit tea based on sensory evaluation were $1,576.0 \pm 32.5$ and $336.5 \pm 26.5 \mu \mathrm{mol}$ TE per $250 \mathrm{~mL}$, respectively. The serving size used for the single dose ingestion $(250 \mathrm{~mL})$ for the determination of postprandial glycemic response and plasma antioxidant activity. The TPC and TEAC per $\mathrm{g}$ of raw ingredient (dried immature bael fruit cuts) were $16.1 \mathrm{mg}$ GAE and $20.2 \mu \mathrm{mol}$ TE, respectively. In a recent study Zhao et al. (2019) showed that TPC of 30 tea (Camellia sinensis) aqueous in- 
Table 3. Mean scores for sensory attributes and Friedman test ranks for different preparations of bael fruit tea

\begin{tabular}{llll}
\hline & $\mathbf{7 8 0}$ & $\mathbf{8 9 2}$ & $\mathbf{5 3 1}$ \\
\hline Mean scores & & & $4.5 \pm 1.2^{\mathrm{b}}$ \\
$\quad$ Color & $5.1 \pm 1.5^{\mathrm{a}}$ & $6.0 \pm 1.1^{\mathrm{a}}$ & $3.5 \pm 1.0^{\mathrm{c}}$ \\
$\quad$ Taste preference & $5.3 \pm 1.0^{\mathrm{a}}$ & $4.3 \pm 1.3^{\mathrm{b}}$ & $3.5 \pm 0.9^{\mathrm{b}}$ \\
$\quad$ After taste & $5.4 \pm 0.8^{\mathrm{a}}$ & $5.3 \pm 1.1^{\mathrm{a}}$ & $3.7 \pm 0.8^{\mathrm{c}}$ \\
$\quad$ Overall acceptance & $5.4 \pm 1.1^{\mathrm{a}}$ & $4.6 \pm 0.9^{\mathrm{b}}$ & $3.6 \pm 1.1^{\mathrm{c}}$ \\
$\quad$ Willingness to drink regularly & $5.1 \pm 1.1^{\mathrm{a}}$ & $4.2 \pm 1.0^{\mathrm{b}}$ & 1.61 \\
\hline Friedman test ranks & & & 1.98 \\
$\quad$ Mean rank & 2.41 & & \\
\hline
\end{tabular}

All values are mean $(n=50) \pm S D$; Values in each row having the same letter are not significantly different $(p>0.05)$.

fusions ranged from 24.8 to $252.6 \mathrm{mg}$ GAE per g of dry weight ( $\mathrm{g}$ DW) of tea. The TEAC values of tea infusions varied from 166.3 to 2,532 $\mu \mathrm{mol} \mathrm{TE} / \mathrm{g} \mathrm{DW}$ (Zhao et al., 2019). It should be noted that bael fruit tea used in the present work contained a lesser TPC and TEAC compared to tea infusions of green, black, oolong, white, yellow and dark teas (Zhao et al., 2019).

\subsection{Effect of herbal teas on glycemic response}

From the sixteen healthy subjects recruited in the study one withdrew after completing two visits due to change of personal work arrangement. In the final analysis 15 subjects (11 males and 4 fe- males) were included. The mean age of subjects was $24 \pm 2 \mathrm{y}$ and the mean body mass index was $21.7 \pm 3.4 \mathrm{~kg} / \mathrm{m}^{2}$. Daily energy, carbohydrate, protein and fat intake of subjects were 1,322 \pm 257 kcal, $216 \pm 49 \mathrm{~g}, 39 \pm 8$, and $36 \pm 9 \mathrm{~g}$, respectively. No adverse effects due to the ingestion of herbal teas were reported during the study period.

Figure 1 and Table 4 present the change of mean PGC of healthy adults over the time from baseline $(0 \mathrm{~min})$ to $120 \mathrm{~min}$. Bael fruit tea showed a lower PGC than the control at each postprandial time point except at the baseline (Figure 1). Several previous studies have shown that repeated administration of aqueous extracts of bael leaves, bark, seeds, fruits was effective in treating hyperglycemic conditions in rats (Kamalakkannan and Prince, 2003; 2005; Maity

180

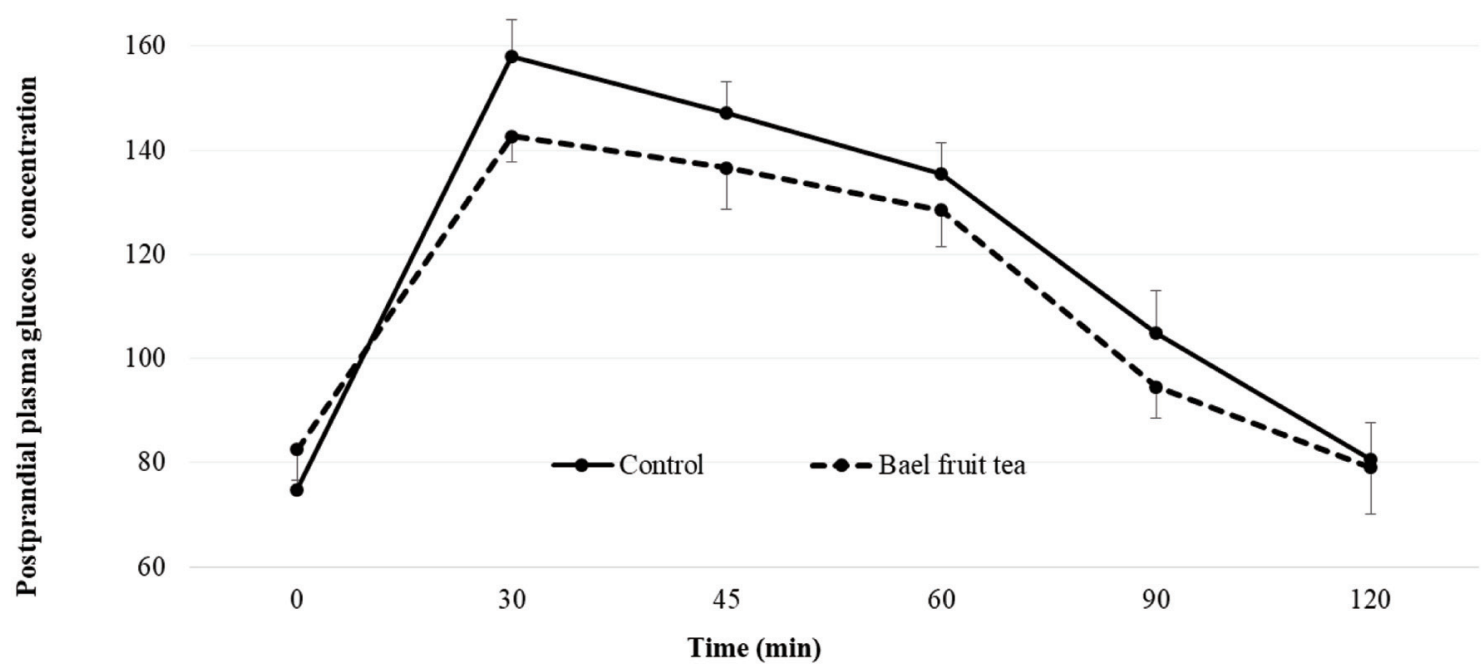

Figure 1. Mean plasma glucose concentration of healthy adults after consuming bael fruit herbal tea and the control.

Table 4. Difference of postprandial plasma glucose response of healthy adults for bael fruit tea compared to the control

\begin{tabular}{lllllll}
\hline & $\mathbf{0} \mathbf{~} \mathbf{m i n}$ & $\mathbf{3 0} \mathbf{~}$ in & $\mathbf{4 5} \mathbf{~}$ in & $\mathbf{6 0} \mathbf{m i n}$ & $\mathbf{9 0} \mathbf{m i n}$ & $\mathbf{1 2 0} \mathbf{m i n}$ \\
\hline Mean difference & -7.89 & 15.9 & 10.5 & 6.9 & 10.5 & 1.54 \\
SEM & 5.58 & 16.4 & 13.7 & 16.3 & 11.9 & 5.99 \\
\hline
\end{tabular}

SEM, Standard error of mean 
Table 5. Plasma antioxidant capacity ( $\mu \mathrm{mol}$ trolox equiv/L) of healthy adults at baseline and 120 min after ingestion of herbal teas

\begin{tabular}{lllll}
\hline & Baseline & $\begin{array}{l}\text { End (120 min } \\
\text { after ingestion) }\end{array}$ & $\begin{array}{l}\text { Difference between } \\
\text { baseline and end }\end{array}$ & $\begin{array}{l}\text { Percentage change (\%) compared } \\
\text { to baseline at the end }\end{array}$ \\
\hline Control & $206.9 \pm 44.1^{\mathrm{a}}$ & $196.1 \pm 43.5^{\mathrm{a}}$ & -10.8 & - \\
Bael fruit tea & $229.1 \pm 27.1^{\mathrm{a}}$ & $397.2 \pm 39.4^{\mathrm{b}}$ & 168.1 & $74.6^{*}$ \\
\hline
\end{tabular}

All values are mean $(n=15) \pm$ SEM; Values in each column with the same letter are not significantly different $(p>0.05)$; Values in each row having the same letter are not significantly different $(p>0.05)$. * Percentage increment of plasma antioxidant capacity of bael fruit tea compared to the respective baseline is significant $(p>0.05)$.

et al., 2009). According to Kamalakkannan and Prince (2003) oral administration of water extract of bael fruit two times per day for 4 weeks in streptozotocin induced diabeteic Wistar rats significantly reduced blood glucose, plasma TBARS, and hydroperoxides.

To the best of our knowledge there are no reports of any human studies on how immature bael fruit tea may improve the postprandial glycemic control. In the present study, the efficacy of single dose administration of bael fruit tea was investigated in healthy humans. The results demonstrated that ingestion of a single dose of $250 \mathrm{~mL}$ of bael fruit tea with $50 \mathrm{~g}$ of glucose challenge had no significant $(p<0.05)$ effect on postprandial hypoglycemic response in healthy adults when compared with the corresponding values at each time point compared to the control.

\subsection{Effect of herbal teas on plasma antioxidant capacity (PAC)}

Plasma antioxidant capacity of healthy subjects was measured at the baseline and $120 \mathrm{~min}$ after ingestion of herbal teas. The test bael fruit herbal tea showed a significant $(\mathrm{p}<0.05)$ increment of PAC compared to the baseline and the change was $74.6 \%$ (Table 5 ). The increment of PAC for bael fruit tea compared to the corresponding baseline was 168.1 TE/L. Villano et al. (2010) demonstrated an increment of PAC in healthy adults after a single dose load of $500 \mathrm{~mL}$ of fermented or unfermented rooibos tea. Furthermore, the increment of PAC was reported for green tea beverage and green tea extract in adults with metabolic syndrome (Basu et al., 2013).

The bael fruit tea showed a significantly higher PAC of 397.2 $\mathrm{TE} / \mathrm{L}$ compared to the control at the end of $120 \mathrm{~min}$ post ingestion (Table 5). This was almost $75 \%$ increment of plasma antioxidant capacity compared to the baseline. In the present work the compositional analysis showed that bael fruit extract contained ellagic acid, protocatechuic acid derivative and resveratrol derivatives (Table 1). All these phenolic compounds are potent antioxidants and exert beneficial effects that prevent and manage non-communicable disease conditions in which oxidative stress plays a major role (Krushna et al., 2012; Muthukumaran et al., 2016; Salehi et al., 2018; Chandrasekara, 2019). Furthermore, the presence of resveratrol and its metabolites in human LDL-cholesterol after moderate intake of red wine has already been reported (Urpí-Sardà et al, 2005). Previously, Krushna et al. (2012) showed that bael fruit extract scavenged superoxide and hydroxyl radicals and nitric oxide in a dose dependent manner in vitro. In the same study, isoproterenol (ISO) induced oxidative stress of rats was ameliorated by repeated use of bael fruit extract for $45 \mathrm{~d}$ by reducing thiobarbituric acid reactive substances (TBARS) and tissue damaged marker enzymes, namely aspartate aminotransferase (AST), lactate dehydrogenase (LDH), alanine transaminase (ALT) and creatinine kinase MB isoenzyme (CK-MB) in the serum. In addition, Krushna et al. (2012) further showed that bael fruit extract elevated antioxidant enzymes such as superoxide dismutase, catalase, glutathione peroxidase, and glutathione-S-transferase and reduced glutathione levels in serum that attenuated oxidative stress induced by ISO in rats.
The foregoing results suggest that bael fruit tea could serve as a potential source of antioxidant compounds and is effective in attenuating oxidative stress that leads to a plethora of non-communicable diseases, including type 2 diabetes.

\section{Conclusion}

Herbal tea prepared with immature dried bael fruits is a rich source of water-soluble phenolic compounds with demonstrated potent antioxidant activities. Bael fruit tea tested in this work was found effective in increasing plasma antioxidant activity with the potential of reducing oxidative stress and help controlling secondary complications of type 2 diabetes and maintaining health and wellness.

\section{Acknowledgments}

This research was supported by the Wayamba University of Sri Lanka through a University research grant (SRHDC/RP/04/18-03) to AC. Dr Gamika Prathapasinghe, Department of Livestock and Avian Sciences, Wayamba University of Sri Lanka was acknowledged for generous support extended by providing the facility of micro centrifuge.

\section{Conflict of interest}

The authors state that there is no conflict of interest to declare.

\section{References}

Akalin, K., Ekiz, A.T., Karakaya, F., Karadag, A., Pelvan, E., Doğan, K., Alasalvar, C., and Aksu, S. (2019). In vivo antidiabetic activities of green and black tea polysaccharides using streptozotocin - induced diabetic mice fed with a high-fat diet. J. Food Bioact. 8: 74-83.

Arul, V., Miyazak, S., and Dhananjayan, R. (2005). Studies on the antiinflammatory, antipyretic and analgesic properties of the leaves of Aegle marmelos Correa. J. Ethnopharmacol. 96(1-2): 159-163.

Badam, L., Bedekar, S., Sonawane, K.B., and Joshi, S.P. (2002). In vitro antiviral activity of bael (Aegle marmelos Corr) upon human coxsackieviruses B1-B6. J. Commun. Dis. 34(2): 88-99.

Baliga, M.S., Bhat, H.P., Joseph, N., and Fazal, F. (2011). Phytochemistry and medicinal uses of the bael fruit (Aegle marmelos Correa):.A concise review. Food Res. Int. 11(44): 1768-1775.

Basu, A., Betts, N.M., Mulugeta, A., Tong, C., Newman, E., and Lyons, T.J. (2013). Green tea supplementation increases glutathione and plasma antioxidant capacity in adults with the metabolic syndrome. Nutr. Res. 33(3): 180-187.

Berman, A.Y., Motechin, R.A., Wiesenfeld, M.Y., and Holz, M.K. (2017). The therapeutic potential of resveratrol: a review of clinical trials. NPJ Precis. Oncol. 1(35): 1-9.

Caesar, L.K., and Cech, N.B. (2019). Synergy and antagonism in natural 
product extracts: when $1+1$ does not equal 2. Nat. Prod. Rep. 36(6): 869-888.

Chandrasekara, A. (2019). Phenolic acids In Melton L. In: Shahidi, F., and Varelis, P. (Ed.). Encyclopedia of Food Chemistry, vol. 3. pp. 535-545.

Chandrasekara, A., and Shahidi, F. (2010). Content of insoluble bound phenolics in millets and their contribution to antioxidant capacity. J. Agric. Food Chem. 58(11): 6706-6714.

Chandrasekara, A., and Shahidi, F. (2018). Herbal Beverages: Bioactive compounds and their role in disease risk reduction - A Review. J. Trad. Comp. Med. 8(4): 451-458.

Chandrasekara, A., Daugelaite, J., and Shahidi, F. (2018). DNA scission and LDL cholesterol oxidation inhibition and antioxidant activities of bae (Aegle marmelos) flower extracts. J. Trad. Comp. Med. 8(3): 428-435.

Charoensiddhi, S., and Anprung, P. (2008). Bioactive compounds and volatile compounds of Thai bael fruit (Aegle marmelos (L.) Correa as a valuable source for functional food ingredients. Int. Food Res. J. 15(3): 287-295.

de Camargo, A.C., Biasoto, A.C.T., Schwember, A.R., Granato, D., Rasera, G.B., Franchin, M., Rosalen, P.L., Alencar, S.M., and Shahidi, F. (2019). Should we ban total phenolics and antioxidant screening methods? The link between antioxidant potential and activation of NF-KB using phenolic compounds from grape by-products. Food Chem. 30(290): 229-238.

de Camargo, A.C., Regitano-d'Arce, M.A.B., Gallo, C.R., and Shahidi, F. (2015). Gamma-irradiation induced changes in microbiological status, phenolic profile and antioxidant activity of peanut skin. J. Funct. Food. 12: 129-143.

Dhankhar, S., Ruhil, S., Balhara, M., Dhankhar, S., and Chhillar, A.K. (2011). Aegle marmelos (Linn.) Correa: A potential source of Phytomedicine. J. Med. Plants Res. 5(9): 1497-1507.

Dhuley, J.N. (2004). Investigation on the gastro protective and antidiarrhoeal properties of Aegle marmelos unripe fruit extract. Hindustan Antibiot. Bull. 45-46(1-4): 41-46.

Falcão, H.G., Silva, M.B.R., de Camargo, A.C., Shahidi, F., Franchin, M., Rosalen, P.L., Alencar, S.M., Kurozawa, L.E., and Ida, E.I. (2019). Optimizing the potential bioactivity of isoflavones from soybeans via ultrasound pretreatment: Antioxidant potential and NF-KB activation. J. Food Biochem. 43(11): e13018.

Gurjar, P.S., Bhattacherjee, A.K., Singh, A., Dikshit, A., and Singh, V.K. (2019). Characterization of nutraceuticals in bael powder prepared from fruits harvested at different developmental stages. IJTK 18(4): 724-730.

Iannitti, T., and Palmieri, B. (2009). Antioxidant therapy effectiveness: an up to date. Eur. Rev. Med. Pharmacol. Sci. 13(4): 245-278.

Jagetia, G., Venkatesh, P., and Baliga, M. (2004). Evaluation of the radioprotective effect of bael leaf (Aegle marmelos) extract in mice. Int. J. Radiat. Biol. 80(4): 281-290.

Jagetia, G.C., and Venkatesh, P. (2005). Radioprotection by oral administration of Aegle marmelos (L.) Correa in vivo. J. Environ. Pathol. Toxicol. Oncol. 24(4): 315-330.

Kamalakkannan, N., and Prince, P.S. (2003). Hypoglycaemic effect of water extracts of Aegle marmelos fruits in streptozotocin diabetic rats. J. Ethnopharmacol. 87: 207-210.

Kamalakkannan, N., and Prince, P.S. (2005). The effect of Aegle marmelos fruit extract in streptozotocin diabetes: A histopathological study. J. Herb Pharmacother. 5: 87-96.

Kim, D., Jeong, S.W., and Lee, C.Y. (2003). Antioxidant capacity of phenolic phytochemicals from various cultivars of plums. Food Chem. 81: 321-326.

Krushna, G.S.S., Kareem, M.A., Reddy, V.D., Padmawathi, P., Hussain, S.A., and Kodidhela, L.D. (2012). Aegle marmelos fruit extract attenuates isoproterenol- induced myocardial oxidative stress in rats. J. Clin. Biochem. Nutr. 50(3): 199-204.

Kumari, D., Chandrasekara, A., and Shahidi, F. (2019). Bioaccessibility and antioxidant activities of finger millet food phenolics. J. Food Bioact. 6: 100-109.

Kumari, D., Chandrasekara, A., Athukorale, P., and Shahidi, F. (2020). Finger millet porridges subjected to different processing conditions showed low glycemic index and variable efficacy on plasma antioxidant capacity of healthy adults. Food Prod. Proces. Nut. 2(13): 1-11.
Kumari, D., Madhujith, T., and Chandrasekara, A. (2017). Comparison of phenolic content and antioxidant activities of millet varieties grown in different locations in Sri Lanka. Food Sci. Nut. 5(3): 474-485.

Kundu, J.K., Shin, Y.K., Kim, S.H., and Surh, Y.J. (2006). Resveratrol inhibits phorbol ester induced expression of COX-2 and activation of NF-kappa $B$ in mouse skin by blocking kappa B kinase activity. Carcinogenesis 27: 1465-1474.

Lee, W.Y., Emmy, H.K.I., Abbe Maleyki, M.J., and Amin, I. (2007). Antioxidant capacity and phenolic content of selected commercially available cruciferous vegetables. Malaysian J. Nutr. 13(1): 71-80.

Li, S., Gosslau, A., Lange, K., and Ho, C.-T. (2019). Profiled tea extracts exemplifying the importance of characterizing food bioactives: opinion piece. J. Food Bioact 5: 1-5.

Maity, P., Hansda, D., Bandyopadhyay, U., and Mishra, D.K. (2009). Biological activities of crude extracts and chemical constituents of Bael , Aegle marmelos (L) corr. Indian J. Exp. Biol. 47: 849-861.

Milton, F. (1937). The use of ranks to avoid the assumption of normality implicit in the analysis of varian. J. Am. Stat. Assoc. 32(200): 675-701.

Misra, P., Pal, N.L., Guru, P.Y., Katiyar, J.C., and Tandon, J.S. (1991). Antimalarial activity of traditional plant against erythrocyte stages of Plasmodium berghei. Int. J. Pharmacognosy. 29(1): 19-23.

Muthukumaran, P., Saraswathy, N., Aswitha, V., Balan, R., Gokhul, V.B., In dumathi, P., and Yuvapriya, S. (2016). Assessment of total phenolic, flavonoid, tannin content and phytochemical screening of leaf and flower extracts from Peltophorum pterocarpum (DC.) Backer ex K. Heyne: a comparative study. Pharmacogn. J. 8(2): 140-143.

Rajadurai, M., and Prince, P.S. (2005). Comparative effects of Aegle marmelos extract and alpha tocopherol on serum lipids, lipid peroxides and cardiac enzyme levels in rats with isoproterenol-induced myocardial infarction. Singapore Med J. 46: 78-81.

Rajan, S., Goki, M., Jenc, P., Brindh, P., and Sujatha, R.K. (2011). Antioxidant and phytochemical properties of Aegle marmelos fruit pulp. Int. J. Curr. Pharm. Res. 1(3): 65-70.

Re, R., Pellegrini, N., Proteggente, A., Pannala, A., Yang, M., and RiceEvans, C. (1999). Antioxidant activity applying an improved ABTS radical cation decolorization assay. Free Rad. Biol. Med. 26(9-10): 1231-1237.

Salehi, B., Mishra, A.P., Nigam, M., Bilge Sener, B., Mehtap Kilic, M., SharifiRad, M., Fokou, P.V.T., Martins, N., and Sharifi-Rad, J. (2018). Resveratrol: A Double-Edged Sword in Health Benefits. Biomedicines 6(3) 91.

Shahidi, F., Ramakrishnan, V., and Oh, W.Y. (2019). Bioavailability and metabolism of food bioactives and their health effects: a review. J. Food Bioact. 8: 6-41.

Singleton, V.L., and Rossi, J.A. (1965). Colorimetry of total phenolics with phosphomolybdic-phosphotungstic acid reagents. Am. J. Enol Vitic. 16: 144-158.

Suvimol, C., and Pranee, A. (2008). Bioactive compounds and volatile compounds of Thai bael fruit (Aegle marmelos (L.) Correa) as a valuable source for functional food ingredients. Int. Food Res. 15: 45-63.

Urpí-Sardà, M., Jáuregui, O., Lamuela-Raventós, R.M., Jaeger, W., Miksits, M, Covas, M.-I., and Andres-Lacueva, C. (2005). Uptake of Diet Res veratrol into the Human Low-Density Lipoprotein. Identification and Quantification of Resveratrol Metabolites by Liquid Chromatography Coupled with Tandem Mass Spectrometry. Anal. Chem. 77(10): 3149-3155.

Villano, D., Pecorari, M., Testa, M.F., Raguzzini, A., Stalmach, A., Crozier, A. and et al (2010). Unfermented and fermented rooibos tea (Aspalathus linearis) increase plasma total antioxidant capacity in healthy humans. Food Chem. 123(3): 679-683.

Yeo, J., and Shahidi, F. (2019). Revisiting DPPH (2,2-diphenyl-1-picrylhydrazyl) assay as a useful tool in antioxidant evaluation: A new IC100 concept to address its limitations. J. Food Bioact. 7: 36-42.

Zhang, H., and Tsao, R. (2016). Dietary polyphenols, oxidative stress and antioxidant and anti-inflammatory effects. Curr. Opinion Food Sci. 8: 33-42.

Zhao, C.-N., Tang, G.-Y., Cao, S.-Y., Xu, X.-Y., Gan, R.-Y., Liu, Q., Mao, Q.-Q., Shang, A., and Li, H.-B. (2019). Phenolic profiles and antioxidant activities of 30 tea infusions from green, black, Oolong, white, yellow and dark teas. Antioxidants 8(7): 215. 